
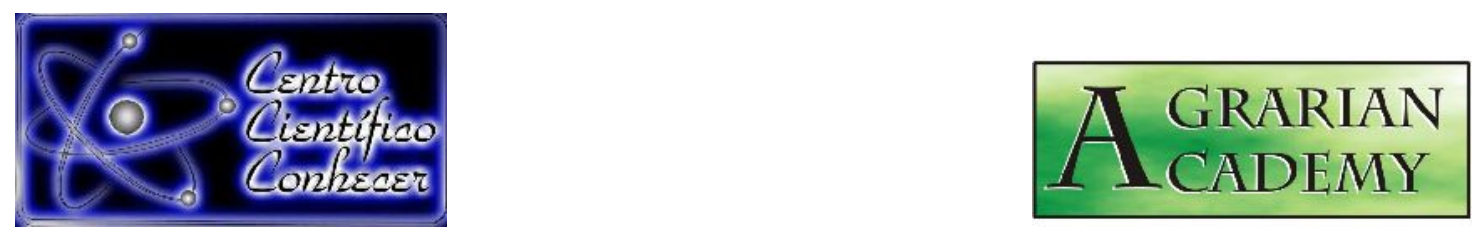

\title{
LEVANTAMENTO DE PROPRIEDADES DE DENSIDADE APARENTE, DENSIDADE DE PARTÍCULAS E POROSIDADE TOTAL EM LATOSSOLOS AMARELO
}

Fátima de Souza Gomes ${ }^{1^{*}}$; Rafael Alves dos santos ${ }^{2}$; Hugo Roldi Guariz ${ }^{3}$

${ }^{1 *}$ Graduanda em Engenharia Agronômica pelo Instituto Federal de Educação, Ciência e Tecnologia Baiano, Campus Guanambi-IFBAIANO, Guanambi-BA, Brasil. E-mail: souzafa86@gmail.com

${ }^{2}$ Graduando em Engenharia Agronômica pelo Instituto Federal de Educação, Ciência e Tecnologia Baiano, Campus Guanambi, IFBAIANO, Guanambi-BA, Brasil.

${ }^{3}$ Docente Doutor do curso de Agronomia do IFBAIANO Campus Guanambi, Guanambi-BA, Brasil.

Recebido em: 20/11/2019 - Aprovado em: 15/12/2019 - Publicado em: 30/12/2019 DOI: 10.18677/Agrarian_Academy_2019b8

\begin{abstract}
RESUMO
A manutenção e recuperação de características físicas podem ser viabilizadas pela adoção de práticas de manejo do solo. Diante disso, objetivou-se determinar a densidade aparente (Da), densidade real (Dr) e porosidade total (PT) do solo sob diferentes sistemas de uso e manejo, em duas profundidades 0,2 $\mathrm{m}$ e 0,2- 0,4 $\mathrm{m}$. Para as análises, o método utilizado fundamentou-se na Embrapa. As áreas foram: pastagens, pomar de goiabeiras, pomar com mamão, palma forrageira e mata nativa. Utilizou-se o delineamento inteiramente casualizado (DIC), com cinco tratamentos (áreas) e 10 repetições (amostras). As médias foram comparadas pelo teste de Tukey a $5 \%$. De acordo com os resultados obtidos, os maiores valores de Ds foram verificados na área sob pastagem, seguida das áreas manejadas. O pisoteio animal na condição de pastagem resultou em menores valores na PT. Os resultados indicam que houve influência dos sistemas de manejo e uso sobre os atributos físicos do solo avaliado.
\end{abstract}

PALAVRAS-CHAVE: Atributos físicos do solo. estrutura do solo. usos do solo.

\section{LIFT DENSITY, PARTICLE DENSITY, AND TOTAL POROSITY LIFTING IN YELLOW LATOSOLS}

\footnotetext{
ABSTRACT

The maintenance and recovery of physical characteristics can be made possible by the adoption of soil management practices. Therefore, the objective was to AGRARIAN ACADEMY, Centro Científico Conhecer - Goiânia, v.6, n.12; p. 79 2019
} 
determine the apparent density (Da), real density (Dr) and total porosity (PT) of the soil under different use and management systems, at two depths $0.2 \mathrm{~m}$ and $0.2-0.4$ $\mathrm{m}$. For the analyzes, the method used was based on Embrapa. The areas were: pasture, guava orchard, papaya orchard, forage palm and native forest. A completely randomized (DIC) design with 5 treatments (areas) and 10 replications (samples) was used. Means were compared by Tukey test at $5 \%$. According to the results obtained, the highest Ds values were verified in the pasture area, followed by the managed areas. Animal trampling in the pasture condition resulted in lower value in PT. The results indicate that there was influence of the management and use systems on the physical attributes of the evaluated soil.

KEYWORDS: Physical attributes of soil. soil structure. land uses.

\section{INTRODUÇÃO}

O solo é a base para a produção de alimentos, constituindo o meio natural para o desenvolvimento das plantas. A manutenção e recuperação de suas características, podem ser viabilizadas pela adoção de práticas de manejo e uso do solo, pois o aumento da intensidade do uso do solo tem levado à degradação dos recursos naturais, provocando impactos negativos sobre o mesmo (SANTOS et al., 2010).

A ocupação de solos considerados de baixa aptidão sem a realização prévia da avaliação da capacidade de uso pode resultar na adoção de sistemas de manejo inadequados levando à degradação, principalmente quando estes, mesmo frágeis, são inseridos ao processo produtivo, diante disso, torna-se válido a realização de pesquisas sobre caracterização dos diferentes solos representativos em uma escala mais detalhada (MOTA ; VALLADARES, 2011).

Sabe-se que, o emprego de sistemas de manejo convencionais, caracterizados pelo revolvimento intensivo do solo através de aração e gradagens, que contribuem a intensificação de processos erosivos e de compactação do solo que resultam em rápida degradação física, química e biológica do solo (FREITAS et al., 2017).

A recuperação, depende também, da adoção do sistema de produção, devido a capacidade de aumentar a matéria orgânica em perfil do solo (palhada), e cobertura do solo evitando a evaporação da água mantendo a temperatura estável, esses fatores são proporcionados exclusivamente, pelo sistema plantio direto que é capaz de manter a produção de grãos em níveis satisfatórios mesmo nos anos em que ocorrem veranicos (COLOMBO et al., 2017).

Diferentes atributos do solo têm sido empregados para caracterizar as modificações resultantes da adoção de diferentes manejos do solo. Os parâmetros utilizados comumente são a densidade e porosidade do solo (CARVALHO et al., 2014), densidade de partículas (BATISTA et al., 2017), umidade do solo (LIMA et al., 2015) resistência do solo à penetração (TAVARES et al., 2014), acumulação de nutrientes e matéria orgânica (MARTINS et al., 2015; GOMES et al., 2015).

A densidade do solo é uma propriedade variável e depende da estrutura e compactação do solo. Esta por sua vez corresponde a massa do solo seco em um determinado volume de solo. O material constituinte do solo tem grande influência sobre o valor da densidade, assim como os sistemas de uso e manejo e tipo de 
cobertura vegetal (BICALHO, 2011).

Os valores de densidade nos solos podem ser extremamente variáveis. Pode-se ter em solos de mesma textura densidades diferenciadas no perfil. A densidade tende a aumentar com a profundidade, variando em função de diversos fatores, como teor reduzido de matéria orgânica, menor agregação, maior compactação, diminuição da porosidade do solo, dentre outros fatores (BICALHO, 2011).

Queiroz-Voltan et al., (2000), constaram que valores de densidade do solo abaixo de $1,5 \mathrm{~kg} \mathrm{dm}^{-3}$, não afetaram o desenvolvimento das cultivares de soja em seu experimento. Reichert et al. (2003) consideram $1,55 \mathrm{mg} \mathrm{m}^{-3}$ como densidade crítica para o bom crescimento do sistema radicular em solos de textura média.

A densidade de partículas (Dp), seguindo a definição de Reinert e Reichert (2006), é expressa pela relação entre a quantidade de massa de solo seco por unidade de volume de sólido do solo. A determinação da Dp, possui grande relevância como indicativa da composição mineralógica, cálculo da velocidade de sedimentação de partículas em líquidos e determinação indireta da porosidade.

De acordo com Brady e Weil (1989), a natureza do mineral predominante determina a densidade de partículas e devido a isso, existe pouca ou até mesmo nenhuma diferença desta característica para uma mesma classe de solo. Tem grande relevância para algumas determinações como a porosidade total do solo, velocidade de sedimentação de partículas em água, grau de saturação com água e dentre outros.

Desse modo, inter-relações da porosidade, densidade do solo e taxa de sedimentação das partículas em meio fluido dependem da densidade destas. A densidade de partículas é um atributo estático, considerando-se que mudanças só seriam perceptíveis em um tempo bastante considerável (BICALHO, 2011).

Vários estudos têm evidenciado que a adoção dos diversos manejos, contribui para a melhoria das características físicas do solo à medida que os cultivos forem se sucedendo, principalmente em razão da cobertura proporcionada, pelas plantas vivas e mortas, que contribuem para a redução da erosão, minimizando as perdas de água, solo e nutrientes além de promover o acúmulo de material orgânico na superfície do solo e redução das emissões de gases de efeito estufa (GEEs) (FAVARATO et al., 2015; OLIVEIRA et al., 2015; SANTOS et al., 2017; COLOMBO et al., 2017).

Diante disso, objetivou-se determinar a densidade aparente (Da), densidade real (Dr) e porosidade total (PT) do solo sob diferentes sistemas de uso e manejo, em duas profundidades $0,2 \mathrm{~m}$ e $0,2-0,4 \mathrm{~m}$.

\section{MATERIAIS E MÉTODOS}

As amostras de solo foram oriundas do município de Guanambi - BA, Micro Região da Serra Geral, com latitude de 14'17'21.73"' sul, longitude de 42ㄴ1'36.54" oeste de Greenwich, altitude de 551 metros. Os solos das áreas em estudo são classificados como Latossolo Vermelho - Amarelo em Latossolo Vermelho (EMBRAPA, 2006), distrófico, típico A fraco, de textura média, fase caatinga hipoxerófila, relevo plano a suave ondulado. O clima da região é semiárido, do tipo Aw pela classificação de Köppen e Geiger (1928), com médias 
anuais de precipitação de 680 milímetros (Figura 1) e temperatura média de $26^{\circ} \mathrm{C}$ (DONATO et al., 2010).

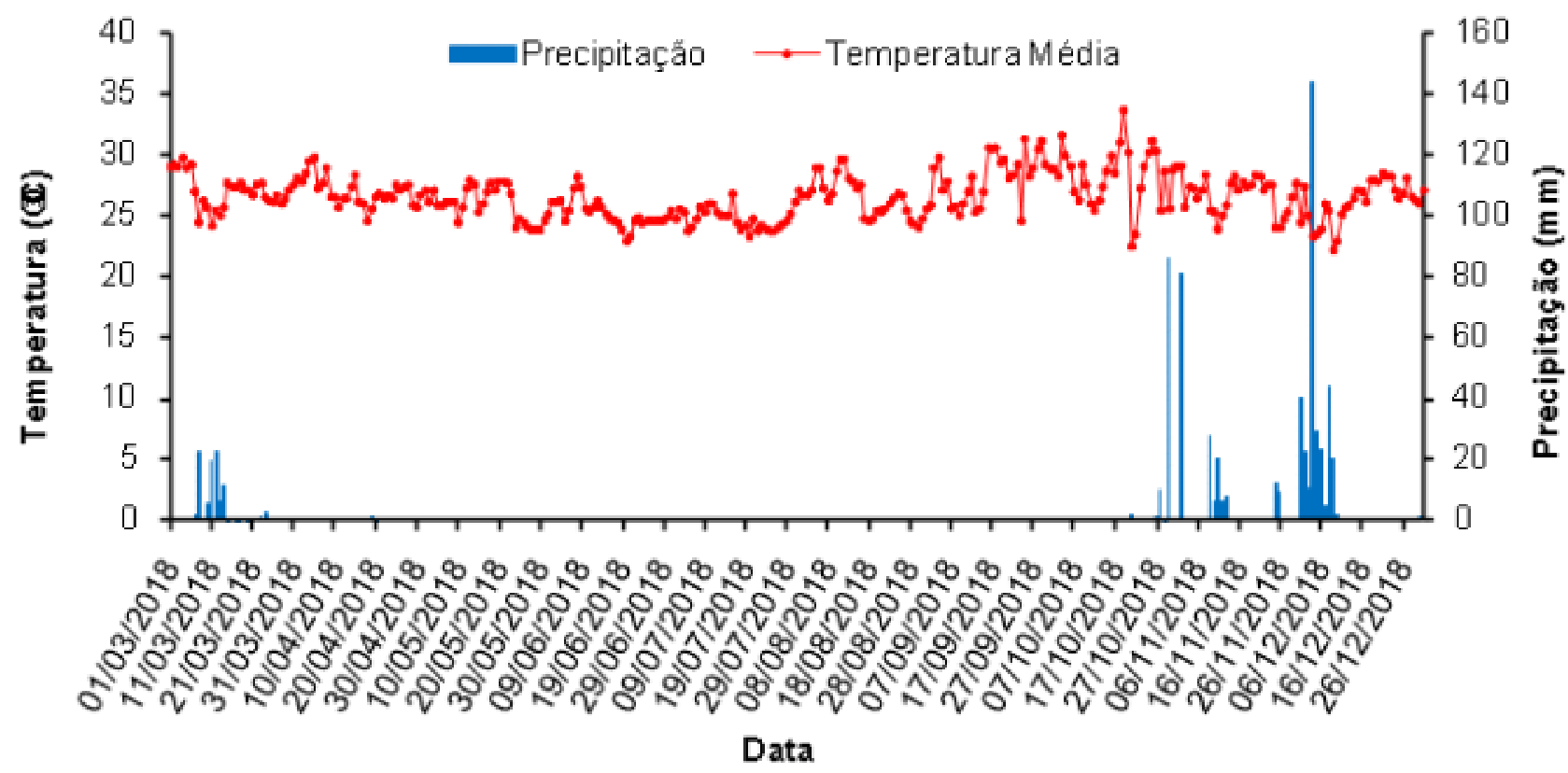

FIGURA 1. Precipitações pluviométricas e temperatura registrada no ano. Fonte: Estação meteorológica automática do Instituto Federal Baiano, Campus Guanambi-BA 2018.

No local de estudo foram selecionadas cinco áreas distintas, limítrofes, sob as mesmas condições topográficas e edafoclimáticas (mesmo solo e clima, textura média, relevo plano), diferenciando-se apenas no uso e manejo adotado, nas profundidades de 0,2 $\mathrm{m}$ e 0,2-0,4 $\mathrm{m}$. As áreas avaliadas foram: pastagens; pomar de goiabeiras, pomar com mamoeiro, cultivo de palma forrageira e mata nativa não disturbada (Quadro 1).

QUADRO 01: Sistemas de manejo do solo e respectivos tipos de solo, Município de Guanambi, BA, 2019

\begin{tabular}{lll} 
Áreas avaliadas & Sistemas de manejo & Tipos de solos \\
\hline A1 & Pastagens & Latossolo Vermelho Amarelo \\
A2 & Pomar de goiabeira & Latossolo Vermelho Amarelo \\
A3 & Pomar com mamoeiro & Latossolo Vermelho Amarelo \\
A4 & Palma forrageira & Latossolo Vermelho Amarelo \\
A5 & Mata nativa & Latossolo Vermelho Amarelo \\
\hline
\end{tabular}

Descrição dos sistemas de manejo do solo: A1 com pastagens, onde a cobertura vegetal predominante é o capim Brachiara sp., que serve de alimento para rebanhos, está estabelecida a uma média de 15 anos. As áreas nas quais encontram-se os pomares A2 e A3 já estão ocupadas com estes usos há mais ou 
menos 10 anos, no pomar houve apenas trabalho de capina e adubação manual, enquanto a área do pomar de goiabeiras, consta de adubações orgânicas constante.

A área 5 , possui palma forrageira estabelecida, com três anos de idade, a área constou de aração e gradagem para o plantio, e é realizada a adubação orgânica com esterco bovino mensalmente. Já a área de mata nativa (A5), representa a situação mais próxima do natural, foi preservada desde o início, devido à pequena profundidade dos solos e alta declividade, o que dificulta a utilização para agricultura. As amostras de solo das áreas avaliadas foram coletadas no segundo semestre de 2018, durante o mês de dezembro. Coletou-se amostras compostas a $0,2 \mathrm{~m}$ de profundidade com auxílio de um trado tipo Uhland.

O delineamento experimental adotado foi o inteiramente casualizado (DIC), sendo constituído por cinco tratamentos e 10 repetições, totalizando 50 unidades experimentais, sendo, cada tratamento uma área com manejo distinto; e as repetições das amostras compostas de solo, a unidade experimental consistiu em uma porção de $50 \mathrm{~g}$ de solo. As variáveis determinadas foram: densidade do solo, densidade aparente e porosidade total.

Para a determinação da densidade aparente ou densidade do solo, foram utilizadas amostras indeformadas retiradas em anel de aço de Kopecky com volume interno de aproximadamente $80 \mathrm{~cm}^{3}$. No laboratório, após pesagem, o solo do anel foi levado para estufa a $105^{\circ} \mathrm{C}$ por aproximadamente 24 horas, até peso constante. Após esse período, as amostras foram pesadas, determinando-se a seguir a densidade do solo (Ds), em $\mathrm{kg} \mathrm{dm}^{-3}$, através da expressão 1 (EMBRAPA, 1997):

$$
\mathrm{Ds}=(1)
$$

Onde: $\mathrm{Ds}=$ densidade do solo; $\mathrm{Ms}=$ massa da amostra de solo seca a $105^{\circ} \mathrm{C}(\mathrm{kg})$; $\mathrm{Vt}=$ volume do anel $\left(\mathrm{dm}^{3}\right)$.

A densidade de partícula ou densidade relativa, foi determinada pelo método do balão volumétrico (EMBRAPA, 1997). O método consiste em determinar o volume de álcool necessário para completar a capacidade de um balão volumétrico, contendo solo seco em estufa. A densidade de partículas foi obtida pela seguinte expressão 2:

$$
\mathrm{Dp}=(2)
$$

Onde: $\mathrm{Dp}=$ densidade de partículas, em $\mathrm{kg} \mathrm{dm}^{-3} ; \mathrm{Ms}=$ massa da amostra de solo seca a $105^{\circ} \mathrm{C}(\mathrm{kg})$ e Vs $=$ volume de sólidos $\left(\mathrm{dm}^{-3}\right)$.

A porosidade total do solo (PT), definida pela relação entre densidade do solo e densidade de partículas (Dp), expressão 3.

$$
\mathrm{PT}=1-\mathrm{x} 100(3)
$$

Onde: $\mathrm{PT}=$ porosidade total $(\%)$; $\mathrm{Ds}=$ densidade do solo, em $\mathrm{kg} \mathrm{dm}^{-3}$ e $\mathrm{Dp}=$ densidade das partículas, em $\mathrm{kg} \mathrm{dm}^{-3}$. 
Os dados obtidos dos atributos físicos do solo foram submetidos a análise de distribuição normal dos dados seguido pela análise de variância. Após realizou-se a comparação das médias efetuadas pelo teste de Tukey $(p<0,05)$. Para realização da análise estatística utilizou-se o programa estatístico Sistema para Análise de Variância - SISVAR (FERREIRA, 2011).

\section{RESULTADOS E DISCUSSÃO}

Os valores médios das variáveis analisadas encontram-se detalhados não Quadro 2. Na comparação de médias constatou-se que, os diferentes usos e manejos do solo influencia significativamente $(p>0,05)$ na qualidade física do solo. Analisando as médias obtidas, observou-se que na profundidade de $0,2 \mathrm{~m}$ (Quadro 2) a maior média para a densidade aparente (Da) foi apresentada pela pastagem com $1600 \mathrm{~kg} \mathrm{~m}^{-3}$, enquanto a área de mata nativa com menor média de densidade (1300 $\left.\mathrm{kg} \mathrm{m}^{-3}\right)$. Os outros sistemas de manejo, não diferiram entre si (pomar com goiabeira e mamão, palma forrageira) com respectivas médias de 1438; 1411 e $1332 \mathrm{~kg} \mathrm{~m}^{-3}$.

Em relação a densidade, os maiores valores médios absolutos mostraram que a camada subsuperficial obteve maior densidade. Entre as condições de uso, foram verificados maiores valores na área de pastagem, seguida das áreas com manejo, evidenciando o efeito das ações antrópicas. Esses maiores valores de densidade do solo na condição de pastagem estão relacionados com o pisoteio dos animais, que promovem a aproximação das partículas do solo resultando em maior densidade do solo.

Todavia, os maiores valores de densidade do solo nas áreas manejadas podem estar atrelados pela redução nos teores de matéria orgânica, em comparação aos solos de mata nativa. Esses resultados corroboram com os citados por Steinbeiss et al. (2009), na qual os mesmos afirmam que a menor densidade do solo nas áreas com mata nativa deve-se aos elevados teores de carbono orgânico e de intensa atividade biológica (fauna e raízes), que constrói canais, cavidades e galerias.

Considerando os resultados relatados por Araújo et al. (2004b), o solo de pastagem e manejo apresentou maiores valores de densidade do solo e menores valores de porosidade total comparado com o solo de mata nativa. Moraes (2013) encontraram maiores valores de Ds e de resistência à penetração em áreas de pastagem, e atribuíram este fato ao tráfego intenso de animais. Para a densidade das partículas (Dp), a 0,2 m, a área com o pomar de mamão teve maior valor (2462 $\mathrm{kg} \mathrm{m}^{-3}$ ), ao tempo que o pomar de goiabeiras, menor Dp, $2317 \mathrm{~kg} \mathrm{~m}^{-3}$. Ao tempo que, a área de pastagem, palma forrageira e mata nativa não diferiram entre si, com a densidade média das partículas de 2444, 2372 e $2411 \mathrm{~kg} \mathrm{~m}^{-3}$.

A densidade de partícula $(D p)$ é um parâmetro que está relacionado a composição mineralógica e orgânica do solo. Conforme Moraes (2013), os elevados valores de densidade de partículas, estão relacionados à presença de altos teores de óxidos de ferro, os quais contribuem para que a média geral da densidade das partículas seja mais elevada do que os valores tradicionais. Assim, solos que apresentam minerais pesado em grande quantidade a Dp será maior, o 
que ocorrerá na área de pastagem.

A área de goiabeira tem adubação orgânica constante como forma de suprimento nutricional para a referida cultura, dessa forma, solos orgânicos apresentam valores de densidade de partículas menores. Corroborando com os resultados obtidos por Burak et al. (2010) que relataram que a Dp não é influenciada por alterações mecânicas, mas sim pelo teor de matéria orgânica encontrada em sua composição. Logo, a densidade de partículas pode ser considerada uma característica bastante estável em relação as modificações repentinas causadas por diferentes sistemas de manejo dos solos.

Verificou-se ainda que, para o atributo porosidade total (PT), na profundidade $0,2 \mathrm{~m}$, notou-se uma maior porcentagem na área de mata nativa com $46 \%$, e menor valor, na área com pastagem 35\%. Quanto a porosidade total, a área de vegetação nativa apresentou o maior valor, resultado já esperado em virtude de a mesma não sofrer impactos e ainda por que mantem a cobertura vegetal, que de acordo com Wendling et al. (2005), é o principal agente de formação e estabilização dos agregados.

Freitas et al. (2017) atribuíram os reduzidos valores da porosidade dos solos cultivados ao aumento da compactação do solo, como a exemplo, as áreas de pastagens, conforme corrobora os resultados desta pesquisa, sendo que a redução do valor desta variável é evidenciada pelo aumento da densidade do solo, pois o intenso pisoteio dos animais, principalmente sob umidade inadequada, proporciona redução drástica no quantitativo de poros.

QUADRO 2- Valores médios de densidade aparente, densidade das partículas e porosidade total (PT) na profundidade de 0,2 m em Latossolo amarelo, Guanambi, BA, 2019

\begin{tabular}{|c|c|c|c|}
\hline Área avaliadas & $\mathrm{Da}$ & $\mathrm{Dp}$ & PT \\
\hline & $\left(\mathrm{kg} \mathrm{m}^{-3}\right)$ & $\left(\mathrm{kg} \mathrm{m}^{-3}\right)$ & $(\%)$ \\
\hline Pastagem & $1600 \mathrm{~A}$ & $2444 \mathrm{~B}$ & $35 \mathrm{C}$ \\
\hline Pomar com goiabeira & $1438 B$ & $2317 \mathrm{C}$ & $38 \mathrm{~B}$ \\
\hline Pomar com mamão & $1411 B$ & $2462 \mathrm{~A}$ & $43 \mathrm{~B}$ \\
\hline Palma forrageira & $1332 \mathrm{~B}$ & $2372 \mathrm{~B}$ & $44 \mathrm{~B}$ \\
\hline Mata nativa & $1300 \mathrm{C}$ & $2411 \mathrm{~B}$ & $46 \mathrm{~A}$ \\
\hline Média & 1412,4 & 2401,2 & 41,2 \\
\hline$\overline{\mathrm{CV}(\%)}$ & 2,0 & 4,2 & 7,35 \\
\hline
\end{tabular}

Médias seguidas pela mesma letra na coluna não diferem entre si (Tukey, $p>$ 0,05). CV (\%) - Coeficiente de variação.

Para as profundidades de 0,2-0,4 $\mathrm{m}$, os valores médios encontram-se detalhados no quadro 3. Observa-se diferença entre os tratamentos com significância de $5 \%(P<0,05)$, na qual a área com o pomar de mamão apresentou a maior Da $1600 \mathrm{~kg} \mathrm{~m}^{-3}$, e a área de mata nativa o menor resultado, $1452 \mathrm{~kg} \mathrm{~m}^{-3}$. Os outros sistemas de manejo, não diferiram entre si (pomar com goiabeira e pastagem, palma forrageira).

Neste sentido, solos com maior densidade apresentam diminuição da porosidade total, redução da permeabilidade e da infiltração de água, quebra dos AGRARIAN ACADEMY, Centro Científico Conhecer - Goiânia, v.6, n.12; p. 85 2019 
agregados e aumento da resistência mecânica à penetração, ocasionando prejuízo ou comprometendo a qualidade física do solo (PEZARICO et al., 2013).

Nos estudos de Freitas et al., (2017), a Ds foi maior nas áreas manejadas, em comparação com a mata nativa, em ambas as profundidades analisadas. Estes resultados estão de acordo com os obtidos por Islam e Weil (2000), Araújo et al. (2004a) e Viana et al. (2011) que constataram um valor médio da Ds significativamente maior em área cultivada comparada com solo de mata natural. Silva e Ribeiro (1992), e Portugal et al. (2010), esses autores ressaltaram ainda que obtiveram resultados similares, comparando solo cultivado com mata nativa.

Os resultados encontrados por Carneiro et al. (2009), Portugal et al. (2010) e Pragana et al. (2012), que observaram aumento da densidade do solo com o uso do solo. A ocorrência de redução de Ds e aumento de Pt no solo com uso agrícola demonstra relação estreita e inversa entre os atributos (CORTEZ et al., 2011).

Os valores de Ds, observados em todas as áreas e manejo estudados, exceto na área de mamão $0,2-0,4 \mathrm{~m}$, ocasionado pelas intensas práticas de manejo, encontram-se abaixo daqueles relatados por alguns pesquisadores como limitantes ou com potencial de causar danos ao crescimento radicular, e consequentemente ao pleno desenvolvimento das culturas.

Os resultados obtidos estão de acordo com observados na literatura que tem constatado que pode ocorrer tal dano nas raízes. Borges et al. (1997), trabalhando em Latossolo Vermelho, textura média, da região do Triângulo Mineiro, observaram que Ds acima de $1,60 \mathrm{~kg} \mathrm{dm}^{-3}$, obtida mecanicamente, por compressão de amostras de solo em anéis de PVC com 100 mm de diâmetro, apresentavam impedimento parcial ao crescimento radicular.

Para a profundidade 0,2 -0,4 $\mathrm{m}$, as áreas diferenciaram estatisticamente, onde a área de pastagem apresentou a maior $\mathrm{Dp},\left(2559 \mathrm{~kg} \mathrm{~m}^{-3}\right)$, em contrapartida, o pomar com goiabeiras obteve menor a média de $\left(2284 \mathrm{~kg} \mathrm{~m}^{-3}\right)$. Pode-se observar que não houve diferenças significativas para a variável porosidade total na profundidade de 0,2-0,4 m apresentando valores próximos de PT, com média de $37,4 \%$.

Já na profundidade de 0,2-0,4 m, a PT não ocorreu diferença significativa, devido ao fato de o manejo ser feito na profundidade superficial, não alterando as camadas mais profundas. Segundo Araújo et al., (2004b), em estudo comparativo das propriedades físicas de um Latossolo Vermelho distrófico, cultivado e sob mata nativa, não verificaram diferenças significativas na PT.

Freitas et al. (2017), em seu trabalho reportaram que, em relação aos atributos físicos, nota-se que a mata é o ambiente que possui os maiores valores de porosidade total. Tais valores foram significativamente menores no solo manejado em comparação com os do solo sob mata nativa. Em geral, espera-se que a o aporte de $\mathrm{MO}$ apresente efeito significativo quanto à $\mathrm{PT}$, pois segundo Silva et al. (2008b), os resultados podem ser justificado por falhas na adoção do sistema, ou ainda de aporte deficitário de palha, além de casos em que a rotação de culturas é realizada com culturas inadequadas à região.

Melloni et al. (2008) também encontraram maior porosidade na vegetação nativa, enquanto a pastagem favoreceu a exposição do solo a processos 
degradativos devido aos problemas de compactação. O fato de a vegetação natural apresentar melhores condições físicas é explicado pelos autores como uma consequência por ser conservado e protegido de ações antrópicas.

A drástica redução da porosidade nos solos cultivados decorre do aumento da compactação do solo, que é evidenciada pelo aumento da densidade do solo (SILVA et al., 2008a; FREITAS, 2011). Solos compactados ou pobres em matéria orgânica apresentam menor porosidade total.

No trabalho de Freitas et al. (2017), a porosidade total (PT) é inversamente proporcional à Ds, sendo influenciada significativamente pelos diferentes usos do solo, nas duas profundidades, com os maiores valores sendo encontrados nas áreas de mata nativa.

QUADRO 3-Valores médios de densidade aparente, densidade das partículas e porosidade total na profundidade de $0,2 \mathrm{~m}-0,4 \mathrm{~m}$ em Latossolo amarelo, Guanambi, BA, 2019

\begin{tabular}{|c|c|c|c|}
\hline Área avaliadas & $\mathrm{Da}$ & $\mathrm{Dp}$ & PT \\
\hline & $\left(\mathrm{kg} \mathrm{m}^{-3}\right)$ & $\left(\mathrm{kg} \mathrm{m}^{-3}\right)$ & $(\%)$ \\
\hline Pastagem & $1535 \mathrm{~B}$ & $2559 A$ & $41 \mathrm{~A}$ \\
\hline Pomar com goiabeira & $1466 \mathrm{~B}$ & $2284 \mathrm{C}$ & $36 \mathrm{~A}$ \\
\hline Pomar com mamão & $1600 \mathrm{~A}$ & $2386 \mathrm{~B}$ & $33 \mathrm{~A}$ \\
\hline Palma forrageira & 1588 B & $2359 \mathrm{~B}$ & $37 \mathrm{~A}$ \\
\hline Mata nativa & $1452 \mathrm{C}$ & $2411 \mathrm{~B}$ & $40 \mathrm{~A}$ \\
\hline Média & 1528,2 & 2399,8 & 37,4 \\
\hline$\overline{\mathrm{CV}}(\%)$ & $\overline{1,02}$ & 0,96 & 9,10 \\
\hline
\end{tabular}

Médias seguidas pela mesma letra na coluna não diferem entre si (Tukey, $p>$ 0,05). CV (\%) - Coeficiente de variação.

Outro aspecto refere-se à porosidade total dos solos que pode ser classificada como porosidade média, com exceção da área com pomar de mamão que se classificam como porosidade baixa, conforme a classificação de laeg (1979) o quadro 4.

QUADRO 4 - Classificação de porosidade e índice de vazios

\begin{tabular}{lll}
\hline Porosidade Total (\%) & Índices vazios & Denominação \\
\hline$>50$ & Maior que 1 & Muito alta \\
$50-40$ & $1,0-0,8$ & Alta \\
$45-35$ & $0,8-0,55$ & Média \\
$<30$ & $0,55-0,43$ & Baixa \\
\hline
\end{tabular}

Fonte: laeg (1974).

A porosidade de um determinado solo influencia na aeração, condução e retenção de água, resistência à penetração e ramificação das raízes no solo e, como consequência, na disponibilidade de água e nutrientes (TOGNON, 1991). A composição de um solo ideal, em relação aos poros, é que estes tenham volume e dimensão adequada para entrada, movimento e retenção de água e ar que atendam às necessidades da cultura (HILLEL, 1980). 


\section{CONCLUSÃO}

Os sistemas de manejo e uso do solo influenciam os atributos físicos do solo.

\section{REFERÊNCIAS}

ARAÚJO, M.A.; TORMENA, C.A.; SILVA, A.P. Propriedades físicas de um latossolo vermelho distrófico cultivado e sob mata nativa. Revista Brasileira de Ciência do Solo, Campinas, v.28, p.337-345, 2004a. Disponível em: <http://dx.doi.org/10.1590/S0100-06832011000100008>. DOI: 10.1590/S010006832011000100008

ARAÚJO, E. A.; LANI, J. L.; AMARAL, E. F. GUERRA, A. Uso da terra e propriedades físicas e químicas de Argissolo Amarelo distrófico na Amazônia ocidental. Revista Brasileira de Ciência do Solo, v. 28, n. 2, p. 307- 315, 2004b. Disponível em: <http://dx.doi.org/10.1590/S0100-06832004000200009>.

DOI: http://dx.doi.org/10.1590/S0100-06832004000200009

BATISTA, P. H. D. B.; ALMEIDA, G. L. P. DE A.; NASCIMENTO, N. V.; SARMENTO, R. M. Variabilidade espacial de atributos físicos do solo sob colheita mecanizada de capim-buffel no agreste Pernambucano. Engenharia na Agricultura /Engineering in Agriculture, v. 25, n. 4, p. 307-317, 2017. Disponível em: <https://doi.org/10.13083/reveng.v25i4.771>.DOI: $10.13083 /$ reveng.v25i4.771

BICALHO, I. M. Um Estudo da Densidade do Solo em Diferentes Sistemas de Uso e

Manejo. Enciclopédia Biosfera-Centro Científico Conhecer, Goiânia, v. 7, n.12, p. 01 - 09, 2011. Disponível em: <http:// http://www.conhecer.org.br/enciclop/2011a/agrarias/um\%20estudo\%20da\%20dens idade.pdf.

BORGES; F. LOMBARDI NETO; G. F. CORRÊA; E. V. S. BORGES; L. M. COSTA. Misturas de gesso e matéria orgânica alterando atributos físicos de um latossolo com compactação simulada. Revista Brasileira de Ciência do Solo, Campinas, v.21, p.125-130, 1997. Disponível em:

<http://dx.doi.org/10.1590/S0100-06831999000100016>. DOI: 10.1590/S010006831999000100016

BRADY, N. C.; WEIL, R. R. Elementos da natureza e propriedades dos solos. Bookman Editora, 2009.

BURAK, D. L.; PASSOS, R. R.; SARNAGLIA, S. A. Utilização de análise multivariada na avaliação de parâmetros geomorfológicos e atributos físicos do solo. Enciclopédia Biosfera, Goiânia, v. 6, n. 9, p. 1-11, 2010. Disponível em: <http://dx.doi.org/10.1590/S010006832011000200011 >.DOI:10.1590/S010006832 011000200011 
CARNEIRO, M. A. C.; SOUZA, E. D. S.; REIS, E. F. R.; PEREIRA, H. S.; AZEVEDO, W. R. A. Atributos físicos, químicos e biológicos do solo de cerrado sob diferentes sistemas de uso e manejo. Revista Brasileira de Ciência do Solo, Viçosa, 33 (1), p. 147-157, 2009. Disponível em: <http://dx.doi.org/10.1590/S010006832009000100016>. DOI: 10.1590/S0100-06832009000100016

CARVALHO, M.A.; RUIZ, H. R.; COSTA, L. M. C.; PASSOS, R. R.; ARAÚJO, C. A. $\mathrm{S}$. Composição granulométrica, densidade e porosidade de agregados de Latossolo Vermelho sob duas coberturas do solo. Revista Brasileira de Engenharia Agrícola e Ambiental, Campina Grande, PB, v.18, n.10, p.10101016, 2014. Disponível em: <http://dx.doi.org/10.1590/18071929/agriambi.v18n10p1010-1016>. DOI:10.1590/18071929/agriambi.v18n10p1010-1016.

COLOMBO, G. A.; LOPES, M. B. S. L.; DOTTO, M. C.; CAMPESTRINI, R.; LIMA, $S$. O. Atributos físicos de um latossolo vermelho-amarelo distrófico sob diferentes sistemas de manejo no cerrado tocantinense. Campo Digital, v. 12, n. 1, 2017. Disponível em: < http://dx.doi.org/ 10.5327/Z2176-947820180366>.DOI: 10.5327/Z2176-947820180366

CORTEZ, J. W; ALVES, A. D. S. A.; MOURA, M. R. D. M.; NAGAHAMA, H. J. N. Atributos físicos do Argissolo amarelo do semiárido nordestino sob sistemas de preparo. Revista Brasileira de Ciência do Solo, 35 (4), p. 1207-1216, 2011. Disponível em: <http://dx.doi.org/10.1590/S0100-06832011000400014>.DOI: $10.1590 /$ S0100-06832011000400014

DONATO, S. L. R.; LÉDO, A. A.; PEREIRA, M. C. T.; COELHO, E. F.; COTRIM, C. E.; Estado nutricional de bananeiras tipo prata sob diferentes sistemas de irrigação. Pesquisa Agropecuária Brasileira, Brasília, v.45, n.09, p.980 - 988, 2010. Disponível em: <http://dx.doi.org/10.1590/S0100204X2010000900007>.DOI: 10.1590/S0100-204X2010000900007

EMBRAPA-Empresa Brasileira de Pesquisa Agropecuária. Centro Nacional de Pesquisa de Solos. Manual de métodos de análise de solo. Ed. 2, p. 212, Rio de Janeiro, 1997.

EMBRAPA-Empresa Brasileira de Pesquisa Agropecuária. Sistema Brasileiro de Classificação de Solos. Ed. 1. P. 354, Brasília, 2006.

FAVARATO, L. F.; SOUZA, J. L. DE; GALVÃO, J. C.; SOUZA, C.; GUARÇONI, R. C. Atributos químicos do solo sobre diferentes plantas de cobertura no sistema plantio direto orgânico. Brazilian Journal of Sustainable Agriculture, v. 5, n. 2, 2015.

Disponível em: $\quad$ http://dx.doi.org/10.21206/rbas.v5i2.312>.DOI: 10.21206/rbas.v5i2.312 
FERREIRA, D. F. Manual do sistema Sisvar para análises estatísticas. Lavras: UFV, 2011.

FREITAS. L. Influência de fragmentos florestais nativos sobre os parâmetros químicos, físicos e microbiológicos de solos cultivados com cana-de-açúcar. Dissertação (Mestrado em Biologia Vegetal), Rio Claro: Universidade Estadual Paulista, 2011. 115 p.

FREITAS, L. ALMEIDA, G. L. P. DE A.; NASCIMENTO, N. V. Indicadores da qualidade química e física do solo sob diferentes sistemas de manejo. Revista Unimar Ciências, v. 26, n. 1-2, 2017. Disponível em : http://ojs.unimar.br/index.php/ciencias/article/view/511. Acesso em: 30 jan 2019.

GOMES, R. L. R. LOPES, M. B. S. L.; DOTTO, M. C. Propriedades físicas e teor de matéria orgânica do solo sob diferentes coberturas vegetais. Revista Eletrônica Faculdade Montes Belos, v. 9, n. 1, 2015. Disponível em: http://www.fmb.edu.br/revistaFmb/index.php/fmb/article/view/167. Acesso em: 30 jan. 2019.

HILLEL, D. Fundamentals of soil physics. Academic Press, Orlando, 1980.

KÖPPEN, W.; GEIGER, R. KLIMATE DER ERDE. Gotha: Verlag Justus Perthes. 1928. Wall-map $150 \mathrm{~cm} \times 200 \mathrm{~cm}$.

IAEG. Classification of rocks and soil for engineering geological mapping. Part I Rock and Soil Materials. Bull. IAEG, n 19, Krefeld, p. 364-371, 1979.

ISLAM, K.R.; WEIL, R.R. Land use effects on soil quality in a tropical forest ecosystem of Bangladesh. Agriculture Ecosystems and Environment, v.79, n. 1, p. 9-19, 2000. Disponível em: <http://10.1016/S0167-8809 (99) 00145-0>. DOI:10.1016 / S0167-8809 (99) 00145-0

LIMA, R.P.; SILVA, A.R.; OLIVEIRA, D.M.S. Análise de trilha de atributos físicos na resistência à penetração de um latossolo amarelo. Revista de Agricultura Neotropical, Cassilândia, MS, v.1, n.1, p.65-74, 2015. Disponível em: http://periodicosonline.uems.br/index.php/agrineo/article/view/216.

MARTINS, E. C. A.; PELUZIO, J. M.; JUNIOR, J. P. M. O.; TSAI, S. M.; NAVARRETE, A. A.; MORAIS, P. B. M. Alterações dos atributos físico-químicos da camada superficial do solo em resposta à agricultura com soja na várzea do Tocantins. Biota Amazônia, v. 5, n. 4, p. 56-62, 2015. Disponível em: $<$ http://dx.doi.org/10.18561/2179-5746/biotaamazonia.v5n4p5662 >.DOI:10.18561/21795746/biotaamazonia.v5n4p56-62 
MELLONI, R.; MELlONI, E. G. P.; ALVARENGA, M. I. N.; VIEIRA, F. B. M. Avaliação da qualidade de solos sob diferentes coberturas florestais e de pastagem no sul de Minas Gerais. Revista Brasileira de Ciência do Solo, Viçosa, v. 32, p. 2461-2470, 2008. Disponível em: <http://dx.doi.org/10.1590/S0100-06832011000100008>.DOI: $\quad 10.1590 /$ S010006832011000100008

MORAES, M.T.; DEBIASI, H.; FRANCHINI, J.C.; SILVA, V.R. Correction of resistance to penetration by pedofunctions and a reference soil water content. Revista Brasileira

Ciência do Solo, v. 36: n. 11, p. 1704-1713, 2012 . DOI: http://dx.doi.org/10.1590/1809-4430-Eng.Agric.v36n3p449-459/2016

MORAES, M. T. Qualidade física do solo sob diferentes tempos de adoção e de escarificação do sistema plantio direto e sua relação com a rotação de culturas. 2013. 205 p. 2013. Tese de Doutorado. Dissertação (Mestrado em Ciência do Solo) -Universidade Federal de Santa Maria, Santa Maria.

MOTA, L. H. S. O.; VALLADARES, G. S. Vulnerabilidade à degradação dos solos da Bacia do Acaraú, Ceará. Revista Ciência Agronômica, v. 10, n. 1, p. 39-50, 2011. Disponível em: <http://dx.doi.org/10.1590/S1806-66902011000100006>. DOI: $10.1590 / S 1806-66902011000100006$.

OLIVEIRA, D.M.S.; LIMA, R.P.; VERBURG, E.E.J. Qualidade física do solo sob diferentes sistemas de manejo e aplicação de dejeto líquido suíno. R. Bras. Eng. Agríc. Ambiental, v.19, n.3, p.280-285, 2015. Disponível em: <http://dx.doi.org/10.1590/1807-1929/agriambi.v19n3p280-285>.DOI:

10.1590/1807-1929/agriambi.v19n3p280-285.

PEZARICO, C. R.; VITORINO, A. C. T.; MERCANTE, F. M.; DANIEL, O. Indicadores de qualidade do solo em sistemas agroflorestais. Revista de Ciências Agrárias, Pernambuco, v.56, n.1, p.40-47, 2013. Disponível em: <http://dx.doi.org/10.4322/rca.2013.004>.DOI: 10.4322/rca.2013.004

PORTUGUAL, A. F.; JUNCKSH, I.; SCHAEFER, C. E. R. G. Estabilidade de agregados em argissolo sob diferentes usos, comparado com mata. Revista Ceres, 57 (4), p. 545-553, 2010. Disponível em: <http://dx.doi.org/10.1590/S0034737X2010000400018>.DOI: 10.1590/S0034-737X2010000400018.

PRAGANA, R. B.; RIBEIRO, M. R.; NÓBREGA, J. C. A.; RIBEIRO, M. R.; COSTA, J. A. Qualidade física de Latossolos Amarelos sob plantio direto na região do cerrado piauiense. Revista Brasileira de Ciência do Solo, 36 (5), p. 1591-1600, 2012. Disponível em: <http://dx.doi.org/10.1590/S0100-06832012000500023>. DOI: $10.1590 /$ S0100-06832012000500023.

QUEIROZ-VOLTAN, R.B.; NOGUEIRA, S.S.S.; MIRANDA, M.A.C. Aspectos da AGRARIAN ACADEMY, Centro Científico Conhecer - Goiânia, v.6, n.12; p. 91 2019 
estrutura da raiz e do desenvolvimento de plantas de soja em solos compactados. Pesquisa Agropecuária Brasileira, vol.35, n.5, p.929-938. mai. 2000. Disponível em: <http://dx.doi.org/10.1590/S00067052006000100016>.DOI:10.1590/S0006870520 06000100016

REICHERT, J. M.; REINERT, D. J.; BRAIDA, J. A. Qualidade do solo e sustentabilidade de sistemas agrícolas. Revista de Ciência Ambiental, v 27, p. 2948, 2003. Disponível em: <http://dx.doi.org/10.5039/agraria.v13i1a5501>. DOI: 10.5039/agraria.v13i1a5501

REINERT, D. J.; REICHERT, J. M. Propriedades físicas do solo. Universidade Federal de Santa Maria, Santa Maria, 2006. Disponível em: <http://dx.doi.org/10.1590/S0100-204X2010000300012.DOI: $\quad$ 10.1590/S0100204X2010000300012

SANTOS, J. T.; ANDRADE, A. P. A.; SILVA, I. F. S.; SILVA, D. S. S.; SANTOS, E. M.; SILVA, A. P. G. S. Atributos físicos e químicos do solo de Áreas sob Pastejo na Micro-Região do Brejo Paraibano. Ciência Rural [online], v. 40, n. 12, p. 24 32. 2010. DOI: http://dx.doi.org/10.1590/S0103-84782010001200008.

SANTOS, O. F.; SOUZA, H. M.; OLIVEIRA, M. P.; CALDAS M. B.; ROQUE C. G. Propriedades químicas de um Latossolo sob diferentes sistemas de manejo. Revista de Agricultura Neotropical, Cassilândia-MS, v. 4, n. 1, p. 36-42, jan./mar. 2017.

Disponível

em

https://periodicosonline.uems.br/index.php/agrineo/article/view/1185>

SILVA, M.S.L.; RIBEIRO, M.R. Influência do cultivo contínuo da cana-de-açúcar em propriedades morfológicas e físicas de solos argilosos de tabuleiro no estado de Alagoas. Revista Brasileira de Ciência do Solo, v. 16, n. 3, p. 397-402, 1992.

SILVA, F.I. SILVA, M.L.N.; FERREIRA, M.M. Propriedades físicas de um Latossolo Vermelho cultivado no sistema plantio direto. Irriga, v.13, n. 1, p. 191-204, 2008a. Disponível em: <http://dx.doi.org/10.5902/19805098>.DOI: 10.5902/19805098

SILVA, Á. P.; TORMENA, C. A.; FIDALSKI, J.; IMHOFF, S. Funções de pedotransferência para as curvas de retenção de água e de resistência do solo à penetração. Revista Brasileira de Ciência do Solo, Viçosa, v. 32, p.1-10, 2008b. Disponível em: <http://dx.doi.org/10.1590/1809-4430-Eng.Agric.v36n3p449459/2016>. DOI: 10.1590/1809-4430-Eng.Agric.v36n3p449-459/2016

STEINBEISS, S.; GLEIXNER, G.; ANTONIETTI, M. Effect of biochar amendment on soil carbon balance and soil microbial activity. Soil Biology and Biochemistry, v. 41, n. 6 , p. 1301- 1310, 2009. Disponível em: <https://doi.org/10.1016/j.soilbio.2009.03.016>.DOI: 10.1016/j.soilbio.2009.03.016 
TAVARES, U.E.; MONTENEGRO, A.A.A.; ROLIM, M.M.; SILVA, J.S.S.; VICENTE, T.F.S.; ANDRADE, C.W.L. Variabilidade espacial da resistência à penetração e da umidade do solo em Neossolo Flúvico. Water Resources and Irrigation Management, Cruz das Almas, BA, v.3, n.2, p.79-89, 2014. Disponível em: <https://doi.org/10.13083/reveng.v25i4.771 >.DOI: 10.13083/reveng.v25i4.771

TOGNON, A. A. Propriedades físico-hídricas do Latossolo Roxo da região de Guairá-SP sob diferentes sistemas de cultivo. 1991. 85 f. Dissertação (Mestrado) Escola Superior de Agricultura de Luiz de Queiroz, Piracicaba, 1991.

VIANA, E.T.; BATISTA, M. A.; TORMENA, C. A.; COSTA, A. C. S.; INOU, T. T. Atributos físicos e carbono orgânico em Latossolo Vermelho sob diferentes sistemas de uso e manejo. Revista Brasileira de Ciência do Solo, v. 35, n. 6, p. 2105-2114, 2011. Disponível em: <http://dx.doi.org/10.1590/S010006832011000600025>. DOI: 10.1590/S0100-06832011000600025.

WENDLING, B.; JUCKSCH, I.; MENDONCA, E.DE S.; NEVES, J. C. L. Carbono orgânico e estabilidade de agregados de um Latossolo Vermelho sob diferentes manejos. Pesquisa Agropecuária Brasileira, 40:487-494, 2005. Disponível em: <http://dx.doi.org/10.1590/S0100-204X2005000500010>. DOI: 10.1590/S0100204X2005000500010 